\title{
Sampling bias misrepresents the biogeographical significance of constitutive mixotrophs across global oceans
}

\author{
Suzana Gonçalves Leles ${ }^{1}$ (D) | Aditee Mitra $^{1}$ (D) | Kevin John Flynn ${ }^{1}$ (D) | \\ Urban Tillmann $^{2}$ | Diane Stoecker ${ }^{3}$ | Hae Jin Jeong ${ }^{4}$ | JoAnn Burkholder ${ }^{5}$ | \\ Per Juel Hansen $^{6}$ | David A. Caron ${ }^{7}$ | Patricia M. Glibert ${ }^{3}$ (D) | Gustaaf Hallegraeff ${ }^{8}$ (D) | \\ John A. Raven ${ }^{9,10}$ | Robert W. Sanders ${ }^{11}$ | Mikhail Zubkov ${ }^{12}$
}

${ }^{1}$ Swansea University, Swansea, United Kingdom

${ }^{2}$ Alfred-Wegener-Institute, HemholtzCentre for Polar and Marine Research, Bremerhaven, Germany

${ }^{3}$ University of Maryland Center for Environmental Science, Horn Point Laboratory, Cambridge, Maryland

${ }^{4}$ School of Earth and Environmental Sciences, College of Natural Sciences, Seoul National University, Seoul, Republic of Korea

${ }^{5}$ Center for Applied Aquatic Ecology, Department of Applied Ecology, North Carolina State University, Raleigh, North Carolina

${ }^{6}$ Marine Biological Section, Department of Biology, University of Copenhagen, Helsingør, Denmark

${ }^{7}$ Department of Biological

Sciences, University of Southern California, Los Angeles, California

${ }^{8}$ Institute for Marine and Antarctic Studies, University of Tasmania, Hobart, Tasmania, Australia

${ }^{9}$ Division of Plant Science, University of Dundee at the James Hutton Institute, Invergowrie, Dundee, United Kingdom

${ }^{10}$ Climate Change Cluster, University of Technology Sydney, Ultimo, New South Wales, Australia

${ }^{11}$ Department of Biology, Temple University, Philadelphia, Pennsylvania

${ }^{12}$ SAMS, Scottish Marine Institute, Oban, United Kingdom

\section{Correspondence}

Aditee Mitra, Swansea University, Singleton Park, Swansea SA2 8PP, UK.

a.mitra@swansea.ac.uk

Funding information

Conselho Nacional de Desenvolvimento

Científico e Tecnológico, Grant/Award

\begin{abstract}
Aim: Most protist plankton are mixotrophic, with potential to engage in photoautotrophy and phagotrophy; however, the ecology of these organisms has been misdiagnosed for over a century. A large proportion of these organisms are constitutive mixotrophs (CMs), with an innate ability to photosynthesize. Here, for the first time, an analysis is presented of the biogeography of CMs across the oceans.

Location: Global marine ecosystems.

Time period: $1970-2018$.
\end{abstract}

Major taxa studied: Marine planktonic protists.

Methods: Records for CM species, primarily from the Ocean Biogeographic Information System (OBIS), were grouped by taxonomy and size to evaluate sampling efforts across Longhurst's oceanic provinces. Biases were evaluated through nonparametric tests and multivariate analysis. Biogeographies of CMs from OBIS data were compared with data from studies that specifically targeted these organisms.

Results: Constitutive mixotrophs of different taxonomic groups, across all size ranges, are ubiquitous. However, strong database biases were detected with respect to organism size, taxonomic groups and region. A strong bias was seen towards dinophytes. Species < $20 \mu \mathrm{m}$, especially non-dinophytes, were least represented, with their recorded distribution limited to coastal regions and to temperate and polar seas. Studies specifically targeting these organisms revealed their distribution to be much wider. Such biases are likely to have occurred owing to a failure to capture and correctly identify these organisms in routine sampling protocols.

Main conclusions: Constitutive mixotrophs are dominant members of organisms traditionally termed "phytoplankton". However, lack of routine protocols for measuring phagotrophy in "phytoplankton" protists has led to widespread misrepresentation of the fundamental nature of marine planktonic primary producers; most express both "animal-like" and "plant-like" nutrition. Our results have implications for studies of the global biogeography of plankton, of food web dynamics (including models) and of biogeochemical cycling in the oceans. 
Number: CNPq 232845/2014-0; Leverhulme Trust, Grant/Award Number: Leverhulme International Networking Grant F00391V

Editor: Derek Tittenso

\section{KEYWORDS}

allometry, biogeography, global, Longhurst, mixotrophy, oceans, phytoplankton, taxonomy

\section{1 | INTRODUCTION}

The term biogeography was coined in the late 19th century, stemming from studies of terrestrial plants and animals (Ebach, 2015). Studies of biogeography have typically focused on terrestrial ecosystems. Since the early 20th century, however, there has been growing recognition of the importance of the biogeography of marine microbes across the Earth's oceans, the single largest continuous ecosystem (Cermeño, de Vargas, Abrantes, \& Falkowski, 2010; Dolan, 2006; Smayda, 1958). Over the last decade, various studies have highlighted technical advancements, such as the development of molecular and statistical techniques and the availability of online databases, as factors contributing to the increase in marine biogeography studies (Biard et al., 2016; Dolan, 2005; Fuhrman et al., 2008; Leles et al., 2017; de Vargas et al., 2015).

Studies of the biogeography of marine microbes (prokaryotes and eukaryotes) have concentrated on functional groups, such as cyanobacteria versus phytoplankton versus microzooplankton, or taxonomic groups, such as diatoms and tintinnids (Cermeño \& Falkowski, 2009; Malviya et al., 2016; Pierce \& Turner, 1993). Most functional or taxonomic groupings have followed the traditional designations of either phototrophs or heterotrophs, akin to the plant-animal dichotomy in terrestrial systems. Flynn et al. (2013) criticized this dichotomy, identifying that the vast bulk of the protist plankton formally labelled as "phytoplankton" or "microzooplankton" are potentially mixotrophic, merging phototrophy and phagotrophy. Subsequently, Mitra et al. (2016) proposed a new functional classification for marine protists to aid the exploration of the proposed new mixotroph-centric paradigm in marine ecology (Mitra et al., 2014; Unrein, Gasol, Not, Forn, \& Massana, 2014; Zubkov \& Tarran, 2008). According to this functional classification, marine protists are broadly divided between six functional groups; two of these align with the traditional non-phagotrophic phytoplankton (notably diatoms) and non-phototrophic microzooplankton, and the other four represent contrasting mixotroph functional groups. The mixotroph groups are divided between those with an innate (constitutive) ability to photosynthesize, the constitutive mixotrophs (CM), and three non-constitutive mixotroph (NCM) groups. The NCMs do not have the innate ability to photosynthesize; they derive their photosynthetic capabilities by incorporating plastids from a range of different prey (generalist NCMs, e.g., Laboea) or from very specific phototrophic prey (specialist NCMs, e.g., Mesodinium) or by enslaving phototrophic prey as symbionts (endosymbiotic NCMs, e.g., Rhizarians).

It has been shown that incorporating mixotrophic organisms within in silico food web studies alters the dominance of different plankton functional groups in freshwater and marine systems (Mitra \& Flynn, 2010; Mitra et al., 2014; Wilken, Huisman, Naus-Wiezer,
\& Van Donk, 2013). An understanding of the true trophic status of plankton, including different mixotrophic types, across biogeographical areas is thus important. Leles et al. (2017) undertook a biogeographical analysis of the NCM functional groups. These NCM organisms are undeniably mixotrophic, because they must feed to acquire phototrophic potential. However, the real trophic status of constitutive mixotrophs is problematic because these organisms may not need to eat frequently if de facto at all (Flynn et al., 2013; Mitra et al., 2016). The default expectation has been to retain the traditional "phytoplankton" label for these organisms. Yet, if they are indeed functional mixotrophs, this traditional label would misrepresent biogeographical distributions and allied trophic dynamics.

In this study, we have undertaken the first global biogeographical analysis of marine protists with a constitutive ability to photosynthesize and that are documented as being significantly mixotrophic (i.e., organisms that are undeniably $\mathrm{CMs}$ ). The $\mathrm{CM}$ group includes various ecologically important taxonomic groups within a wide range of sizes, such as species of picoplankton and nanoplankton in oligotrophic oceans and polar regions (Stoecker \& Lavrentyev, 2018), and various harmful algal bloom species in coastal waters (e.g., Karlodinium spp., Alexandrium spp.) that result in fish deaths and closure of aquaculture facilities (Mitra et al., 2016; Shumway, Burkholder, \& Morton, 2018; Stoecker, Hansen, Caron, \& Mitra, 2017). Biogeographical analysis of this important group of planktonic protists will aid our understanding of the impacts of environmental drivers on community composition and ecosystem functioning, especially in the face of climate change events. In our analyses, we specifically identify how biases in the scientific community's perception of these organisms, in addition to sampling methods, impact on our understanding of their biogeography.

\section{2 | METHODS}

We conducted a global analysis of field data for different groups of CMs. Constitutive mixotrophs are defined according to Mitra et al. (2016); these are planktonic protists with an inherent capability to photosynthesize and a demonstrable potential to engage in phagotrophy for their nutritional needs. Traditionally, mixotrophy within many planktonic phototrophs has included phototrophy plus osmotrophy (i.e., uptake of dissolved organic substances; e.g., Burkholder, Glibert, \& Skelton, 2008; Glibert \& Legrand, 2006). Here, however, we focus on photoautotrophic protists that engage in phagotrophy, because osmotrophy appears to be ubiquitous in protists; thus, it is assumed here that all species are capable of osmotrophy (see Flynn et al., 2013; Mitra et al., 2016). 


\section{1 | Data compilation}

Data were compiled according to species name. AlgaeBase (http://www. algaebase.org/) was used to resolve synonyms and basionyms of various species. Using expert knowledge within our team (authors), we first assembled a database of all protist species known to be CMs (Supporting Information Appendix S1, Table S1.1); the definitions of Mitra et al. (2016) were used to differentiate between CMs and strict autotrophs (i.e., phytoplankton). We did not consider coccolithophorids; to date, there has been only one published study reporting phagotrophic activity by the cosmopolitan species Emiliania huxleyi (Rokitta et al., 2011).

Data for the global distribution of the CMs within our list were acquired through interrogation of the Ocean Biogeographic Information System database (OBIS; http://www.iobis.org/) on 20 January 2018 (Supporting Information Appendix S2, Table S2.1). Geographical coordinates corresponding to the locations where the CMs were recorded were obtained. Records with possible spatial errors, such as data points located inland, were excluded from the analysis. Georeferenced occurrence data were retrieved from OBIS using the "devtools" and "robis" packages in R (R Core Team, 2017). Other packages in $\mathrm{R}$ used for data compilation and visualization were "rgdal", "plyr", "ggplot2", "ggalt" and "gridExtra".

In order to ensure that we captured distribution data of CMs across different size classes, we conducted a survey of published literature in the electronic databases ISI Web of Science and Elsevier on 20 January 2018. For all data sources please see Appendix 1. Smaller planktonic protists are rarely, if ever, identified down to species level in field surveys. The aim of these surveys was therefore to obtain records from studies that specifically targeted known $\mathrm{CMs}$ in the nanoplankton spectrum (2-20 $\mu \mathrm{m}$ in length). These studies, although not species specific, reported in situ measurements of the abundance of actively feeding mixotrophic nanoflagellates (i.e., CMs $<20 \mu \mathrm{m}$ in length) or the relative contribution of picoand nano-CMs to total bacterivory by flagellates. Geographical coordinates were retrieved from each of these studies (Supporting Information Appendix S2, Table S2.2) in order to compare these data with species-specific data obtained from the OBIS database.

\section{2 | Spatial analysis}

Records compiled from online databases were aligned with the biogeographical classification of the ocean according to Longhurst (2007). As in the study by Leles et al. (2017), the 54 biogeographical provinces proposed by Longhurst (2007) were grouped into seven principal biomes according to primary production and physical forcing: mediterranean sea, coastal seas, polar seas, temperate seas, oligotrophic gyres, coastal upwelling, and equator (Supporting Information Appendix S1, Table S1.2). However, owing to a lack of data we did not include the coastal upwelling biome in our analysis. Grids corresponding to Longhurst provinces used in the maps were obtained from http://www.marineregions.org/. Geographical coordinates corresponding to the exact location where the CM species were found were then aligned with biogeographical provinces. The records obtained for each species within each biogeographical province were exploited to produce global distribution maps.

\section{3 | Data analysis}

The biogeography of CMs was investigated according to taxonomy and size classes across different oceanic provinces. Species size was obtained from the literature (Berge, Hansen, \& Moestrup, 2008; Hoppenrath \& Leander, 2007; Jang, Jeong, Kwon, \& Lee, 2017; Kang et al., 2011; Lim et al., 2015; Nézan \& Chomérat, 2009; Ok, Jeong, Lim, \& Lee, 2017; Tomas, 1997; Yoo et al., 2010) and online repositories (http://nordicmicroalgae.org; http://www.sccap.dk; http://www. marinespecies.org). Global distribution maps were generated to visualize the presence of each taxonomic group within each size class according to the biogeographical provinces. The sampling locations from all 178 cruises included in the analysis were also mapped in order to compare the biogeographical patterns with the total sampling effort. It is noteworthy that we did not assume a priori that all taxonomic groups should contain individuals within all size classes; indeed, that is not the case. We used expert knowledge and the literature to identify size class boundaries within each taxonomic group. For example, there are no known species within prasinophytes, chrysophytes and haptophytes that are $>15 \mu \mathrm{m}$ in size (measured across the major cell axis). Likewise, all known raphidophyte species are $>10 \mu \mathrm{m}$. Although there are some suggestions of the presence of so-called picoplanktonic marine dinoflagellates $(<5 \mu \mathrm{m})$, this information is derived from initial sequence data only (Lin, Zhang, Hou, Miranda, \& Bhattacharya, 2006; Moon-van der Staay, De Wachter, \& Vaulot, 2001); thus, we could not include such organisms in this analysis. Dinophytes were, therefore, not assumed to occur within the $<5 \mu \mathrm{m}$ size class.

Potential biases related to size and location, when tracing the global distribution of CMs, were analysed quantitatively. For this, we used the mean number of records obtained for each size class across different oceanic biomes. Our dataset did not follow a normal distribution; therefore, Kruskal-Wallis rank tests (results reported as $\mathrm{H}=$ test statistic, $\mathrm{p}$ = significant value) were used to evaluate the effect of size and of biome on CM distribution. Species were grouped according to size within the different oceanic biomes to test for differences among size classes and across the biomes. Post hoc nonparametric tests (Dunn's test) were performed to identify pairs of size classes or oceanic biomes that were significantly different from each other. The same procedure was performed to evaluate the potential bias related to CM taxonomy and location, grouping species according to taxonomy instead of size to test for any differences between taxonomic groups and across the biomes. These analyses were conducted using the "dunn.test" package in R.

Dissimilarities between occurrence patterns of CM species across the different biogeographical provinces were explored using the non-metric multidimensional scaling (NMDS) technique; this is akin to the analysis undertaken by Leles et al. (2017) on NCMs. The georeferenced data compiled from OBIS (Supporting Information Appendix S2, Table S2.1) were used to build a matrix with the number of occurrences for each species within each of the 54 
Longhurst's biogeographical provinces. The $\mathrm{CM}$ species were then grouped according to size and taxonomy. This analysis thus enables positioning of species and biomes within a two-dimensional space; the former are placed with respect to their distribution across the biogeographical provinces and the latter according to species occurrence. Merging the positions of both species and biomes allowed us to explore the placement of species with respect to each other and in relationship to the different biomes. The distance matrix used in the NMDS analysis was calculated after square root transformation using the Bray-Curtis distance. The NMDS was performed using the "metaMDS" function ("vegan" package in R). Progressively lower numbers of dimensions ( $k=$ from 5 to 2 ) were used in order to attain the value of $k$ that provided the lowest stress value (Legendre \& Legendre, 1998).

The volume of seawater analysed will inevitably influence the identification of rare species (i.e., those present in low abundances). However, we could not account for this factor because most publications do not report the volume sampled and analysed and, therefore, this information could not be retrieved from OBIS. Even if this information were available, the volume of water that ideally should be analysed can be highly variable depending on the trophic status of the system (e.g., larger volumes of water should be inspected in oligotrophic waters compared with eutrophic systems, and depending on bloom seasonality); additional knowledge on the different marine ecosystems investigated would be required to interpret such data. Moreover, we would expect a minimal effect in our biogeographical analysis because we grouped CMs into different taxonomic groups and size classes.

\section{3 | RESULTS}

The compiled list of CMs includes 80 species across the different taxonomic groups of primarily cryptophytes, chrysophytes, haptophytes, prasinophytes, raphidophytes, dinophytes, chlorarachniophytes and synchromophytes (Supporting Information Appendix S1, Table S1.1). Nearly 250,000 records were obtained from OBIS for 51 of the 80 species that composed the initial species list; these species were placed into taxonomic groups and five size classes (Supporting Information Appendix S2, Table S2.1). The global distributions of $\mathrm{CMs}$ across the different biogeographical provinces were mapped according to taxonomic groups and allometrics (Figure 1). At least one record was necessary to assume the presence of a species within a province; thus, only five taxonomic groups were mapped (Figure 1).

These maps demonstrate a strong bias in the available data towards larger species, and specifically, towards dinophytes. Nearly $50 \%$ of the constitutive mixotrophic species were $>20 \mu \mathrm{m}$; except for two raphidophytes, all species $>20 \mu \mathrm{m}$ were dinophytes. The dearth of data for other CM groups across the different size classes is indicated by the "non-coloured" (white) biogeographical maps in Figure 1. In order to compare these biogeographical patterns with the total sampling effort, we also mapped the sampling locations from all 178 cruises included in the analysis (Supporting Information Appendix S3, Figure S3.1). From this it can be seen which biogeographical provinces were visited at different points in time and space but were not associated with the presence of a CM group (white biogeographical provinces in Figures 1 and 2 versus Supporting Information Appendix S3, Figure S3.1).
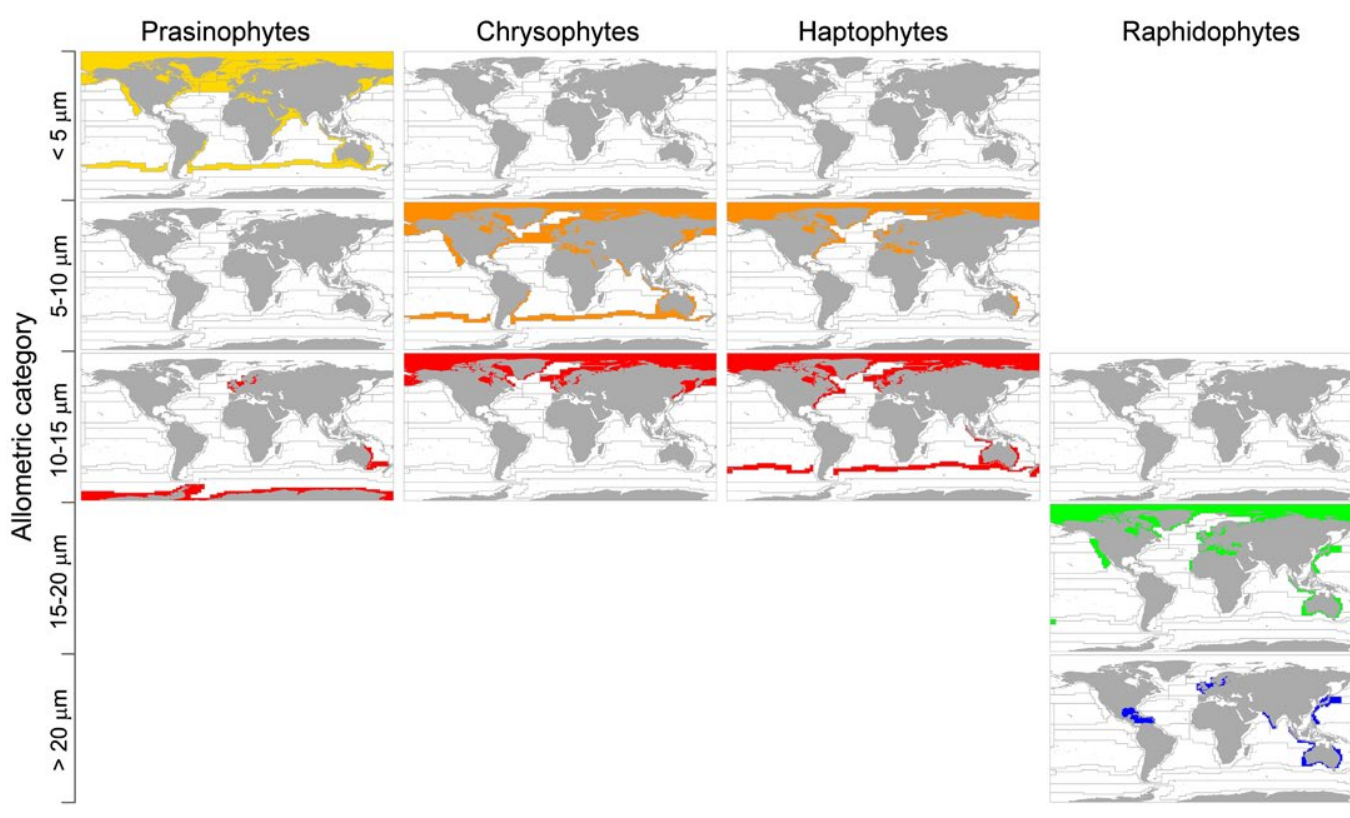

Dinophytes

FIGURE 1 Global distribution of constitutive mixotrophs across Longhurst's biogeographical provinces. Distribution maps are shown for different groups (prasinophytes, raphidophytes, haptophytes, chrysophytes and dinophytes) across different size classes (maximum cell dimension: yellow, < $5 \mu \mathrm{m}$; orange, 5-10 $\mu \mathrm{m}$; red, 10-15 $\mu \mathrm{m}$; green, 15-20 $\mu \mathrm{m}$; blue, > $20 \mu \mathrm{m}$ ). Colour-cast provinces indicate the presence of constitutive mixotrophs; white provinces indicate no data. The absence of maps (i.e., white spaces) indicates that there are no known species of that size class within that taxonomic group. See also the Supporting Information (Appendix S2, Table S2.1) [Colour figure can be viewed at wileyonlinelibrary.com] 
The potential for biases relating to species size, taxonomic grouping and location were tested using quantitative data (Supporting Information Appendix S3, Figure S3.2). The number of records differed significantly among size classes, with a clear bias towards larger size classes $(H=11.8, p=.02$; Supporting Information Appendix S3, Figure S3.2a). Post hoc comparisons confirmed that sampling effort was highest for species with maximum cell dimension > $20 \mu \mathrm{m}$ (Figure 2a; Supporting Information Appendix S4, Table S4.1). Differences were also found when comparing taxonomic groups $(H=12.2, p=.02$; Supporting Information Appendix S3, Figure S3.2b). The number of records obtained for dinophytes was significantly higher than those retrieved for any other taxonomic group, and no significant difference was found among the other groups (Figure 2b; Supporting Information Appendix S4, Table S4.2).
We also tested whether the number of records varied across biomes for each dataset (i.e., grouped by size or by taxonomy; Supporting Information Appendix S3, Figure S3.2), and there were significant differences in both analyses $(H=13.6, p=.02$ and $H=11.2, p=.05$, respectively). Fewer records were available from oligotrophic gyres and equatorial regions compared with other biomes (Supporting Information Appendix S3, Figure S3.2; Appendix S4, Tables S4.3 and S4.4); indeed, data within oligotrophic gyres and equatorial regions were available primarily for dinophytes, except for one record of a raphidophyte species (Figure $2 \mathrm{~b}$ ). The analysis revealed no clear difference among the other biomes (Supporting Information Appendix S4, Tables S4.3 and S4.4).

The relationships between size classes and taxonomy in the global distribution of CMs were explored through the NMDS analysis

(a)
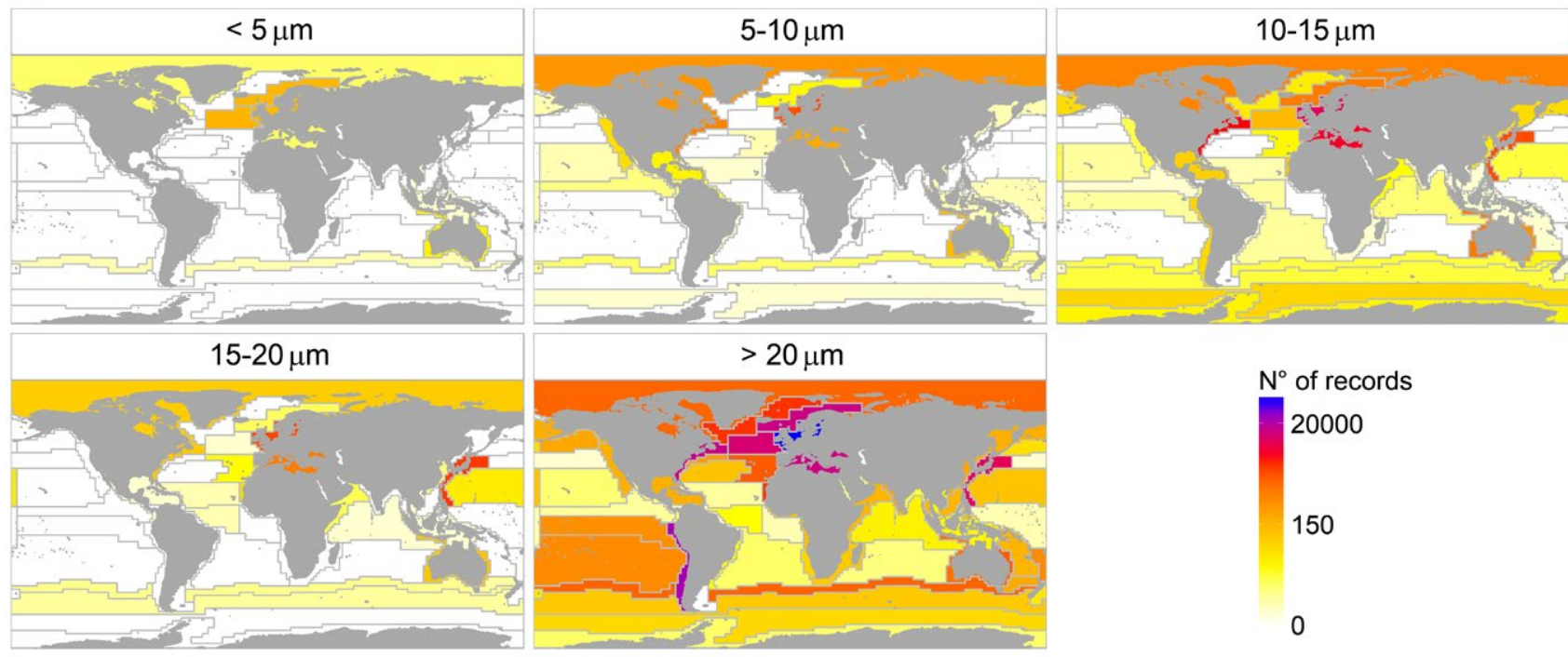

(b)
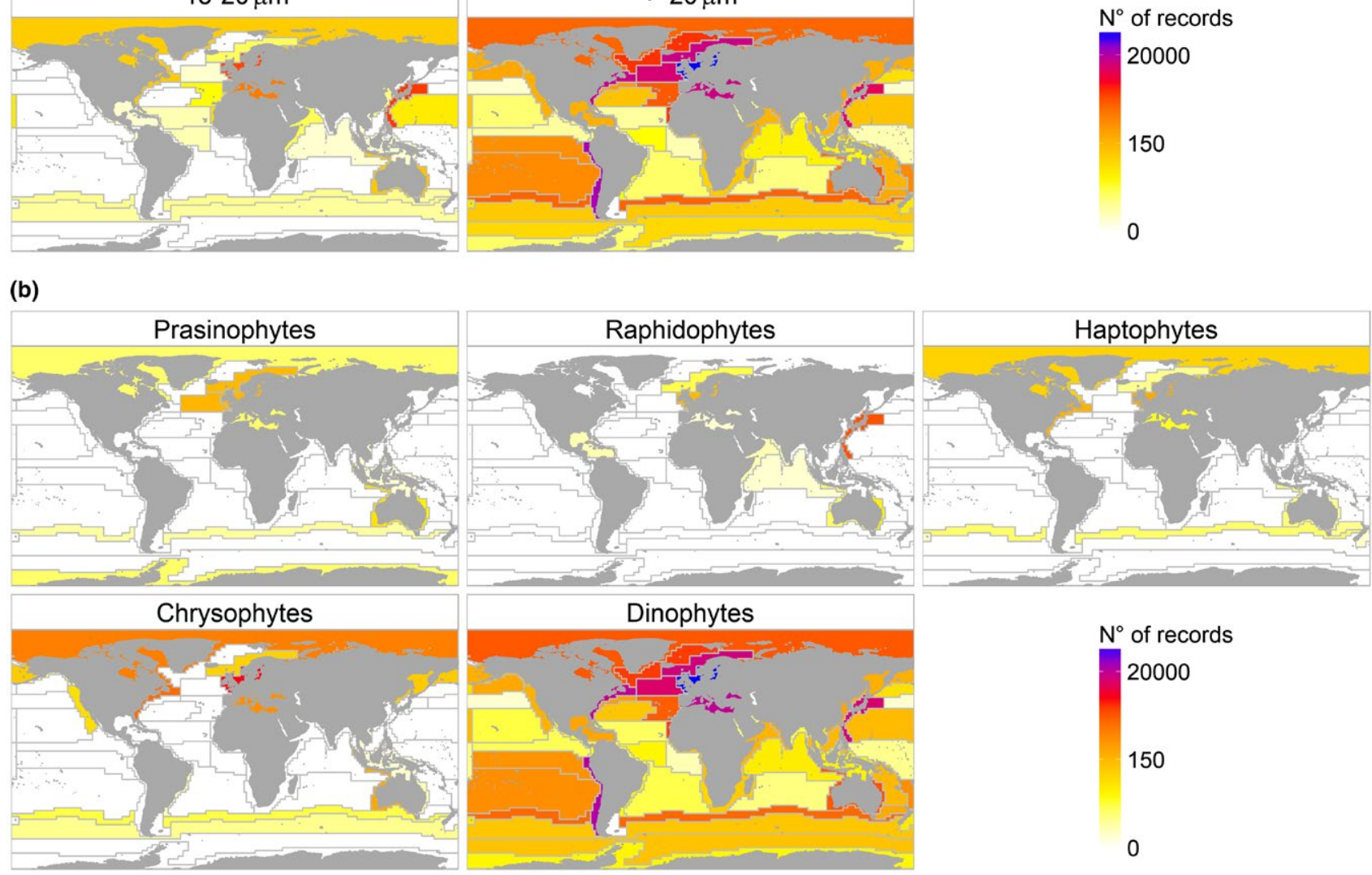

FIGURE 2 Number of records for constitutive mixotrophs across Longhurst's biogeographic provinces. (Supporting Information Appendix S1, Table S1.2 and Appendix S2, Table S2.1). The number of records is provided for: (a) different size classes (length, in micrometres); and (b) different taxonomic groups. See also the Supporting Information (Appendix S3, Figure S3.2). Note that number of records are log-scaled. [Colour figure can be viewed at wileyonlinelibrary.com] 
(Figure 3). Our analysis revealed dinophyte species within the larger size class (> $20 \mu \mathrm{m}$ ) closer to the different biomes, thus displaying a broader geographical distribution compared with other species (Figure 3). The different colours in this figure allow the reader to discern that different taxonomic groups have different distribution patterns. Through reference to the different symbols (Figure 3), it can be seen clearly that size and taxonomy are not independent, and most species of dinophytes are $>20 \mu \mathrm{m}$, whereas most species within other groups are $<20 \mu \mathrm{m}$. However, even among dinophytes there were various outliers, indicating a bias towards focusing on sampling species $>20 \mu \mathrm{m}$ in field studies; Alexandrium andersonii and Fragilidium subglobosum are examples of these "outlier" large dinophytes that ordinated closer to species belonging to other taxonomic groups, such as the haptophyte Prymnesium polylepis and the prasinophyte Cymbomonas tetramitiformis.

Non-dinophyte species $<20 \mu \mathrm{m}$ were the least represented group of CMs. To illustrate further the under-representation of these groups within global databases, and thus the incomplete status of global distribution data, we plotted the data available for these groups from generic studies (Figure 4) and from studies that specifically targeted these groups (Supporting Information Appendix S2). A total of 48 records from 21 studies were located when interrogating studies that specifically targeted known $\mathrm{CMs}$ in the nanoplankton spectrum (2-20 $\mu \mathrm{m}$; Supporting Information Appendix S2, Table $\mathrm{S} 2.2$ ). It should be noted that these studies do not provide speciesspecific information; unless a sampling study specifically targets

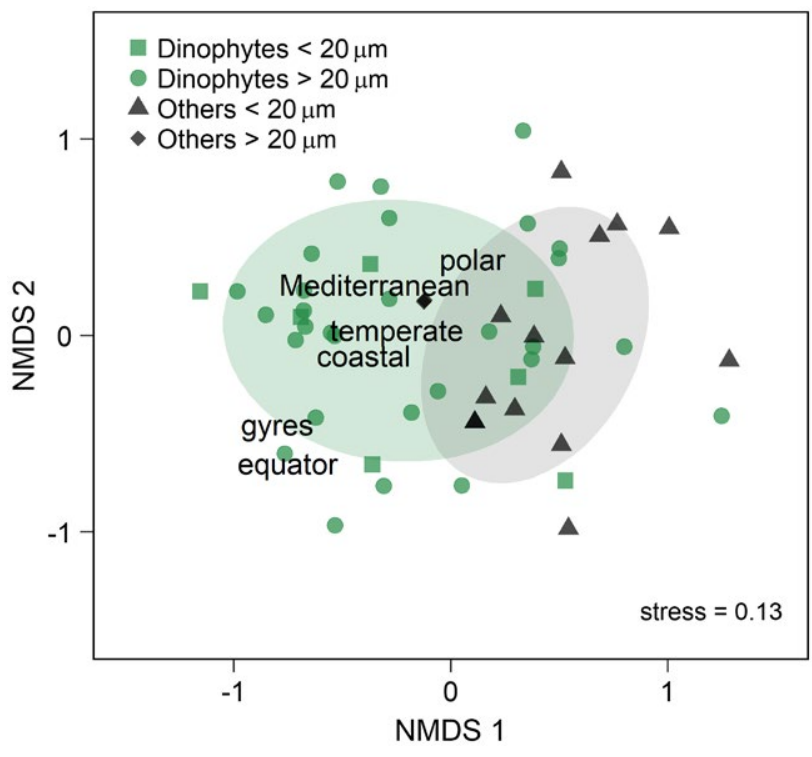

FIGURE 3 Spatial distribution of constitutive mixotrophs from non-metric multidimensional scaling (NMDS) analysis. The NMDS ordination was based on the number of records observed for each species within each biogeographical province; biomes were primarily derived from provinces (Supporting Information Appendix S3, Figure S3.3). Each symbol represents a species that was grouped by taxonomy (different colours) and by size and taxonomy (different symbols). Ellipses are shown at $75 \%$ confidence interval and were used to define dinophytes (green) and other groups (grey) [Colour figure can be viewed at wileyonlinelibrary.com] smaller CM species and uses specialist identification methods and skills, it is highly unlikely, and often impossible, for these taxa to be identified to species level using standard light microscopy within generic sampling protocols. Therefore, the maps derived using data from the generic versus the specific studies present very different outputs (Figure 4). The map obtained from the generic data depicts a limited distribution pattern for $\mathrm{CMs}<20 \mu \mathrm{m}$, with occurrences recorded in coastal regions and in temperate and polar seas (Figure 4a). In contrast, studies that have targeted these species show their distribution largely to encompass open oceans, including regions closer to the equator and within oligotrophic gyres in the Atlantic and the Pacific Oceans (Figure 4b).

\section{4 | DISCUSSION}

Our results indicate a clear bias in the data for the biogeographical distribution of CMs across and within taxonomic groups, different size spectra and Longhurst's oceanic regions. This appears primarily to be a reflection of the difficulties associated with sampling and identification of diagnostic features for small cells in natural water samples. Nevertheless, the wide-scale distributions of CMs of various sizes across the different provinces in the global oceans indicate the importance of considering this mixotroph functional group in studies of protist biogeography and in ecology.

Our current knowledge of CM species distribution remains incomplete primarily owing to various biases in the data within global repositories. Even though it is now recognized that most eukaryote "phytoplankton" groups, with the important exception of diatoms, have the potential to demonstrate mixotrophy (Flynn et al., 2013; Stoecker et al., 2017), clear evidence of mixotrophy has been obtained for < 150 species (Supporting Information Appendix S1, Table S1.1; Leles et al., 2017). To place this in context, the total number of "phytoplankton" species is (as a guesstimate), often rounded to the nearest thousand within a major grouping (phylum).

Our work is the first attempt to document the biogeographies of organisms that are undeniably CMs (Figures 1, 2; Supporting Information Appendix S2, Table S2.1). During interrogation of the online databases, we assumed that the species detected were originally identified and reported correctly. An allied challenge is to determine which species indeed express phagotrophy. A recent study suggests that standard methodologies for detecting phagotrophy in field plankton samples are inappropriate for use on these organisms and has most probably resulted in non-identification of CM activity (Anderson, Jürgens, \& Hansen, 2017). Although Anderson et al. (2017) focused on nano-CMs, their findings suggest that similar methodological problems occur widely, which could easily result in serious misinformation in the protist records of the different databases.

Studies that specifically target CMs have various limitations. Quantitative estimates of abundance are challenging because the current methods can only account for mixotrophs that were actively feeding at the time of the sampling/experiment (Gast, 
(a)

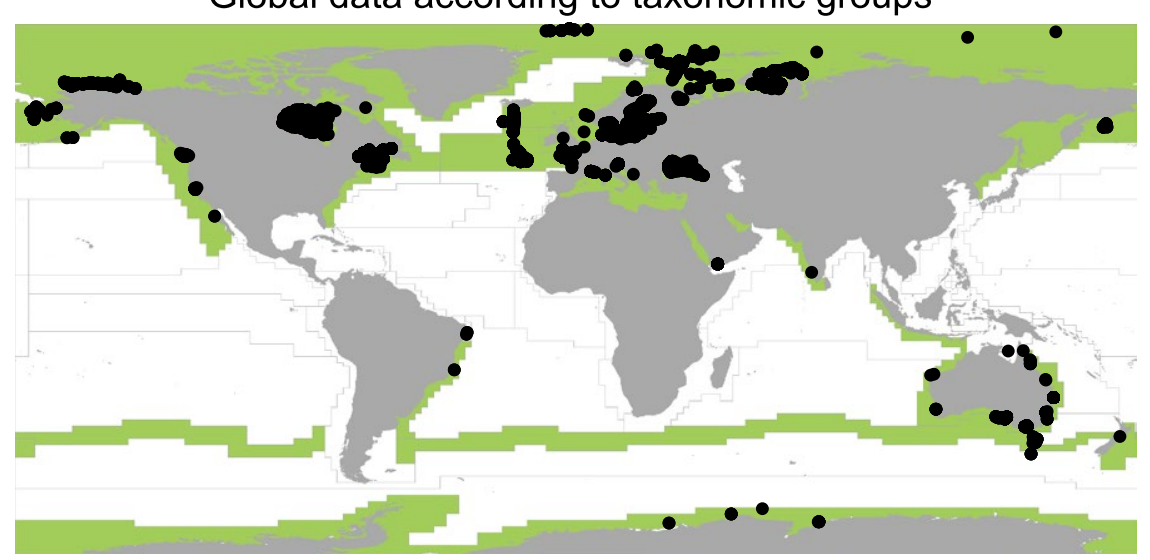

(b)

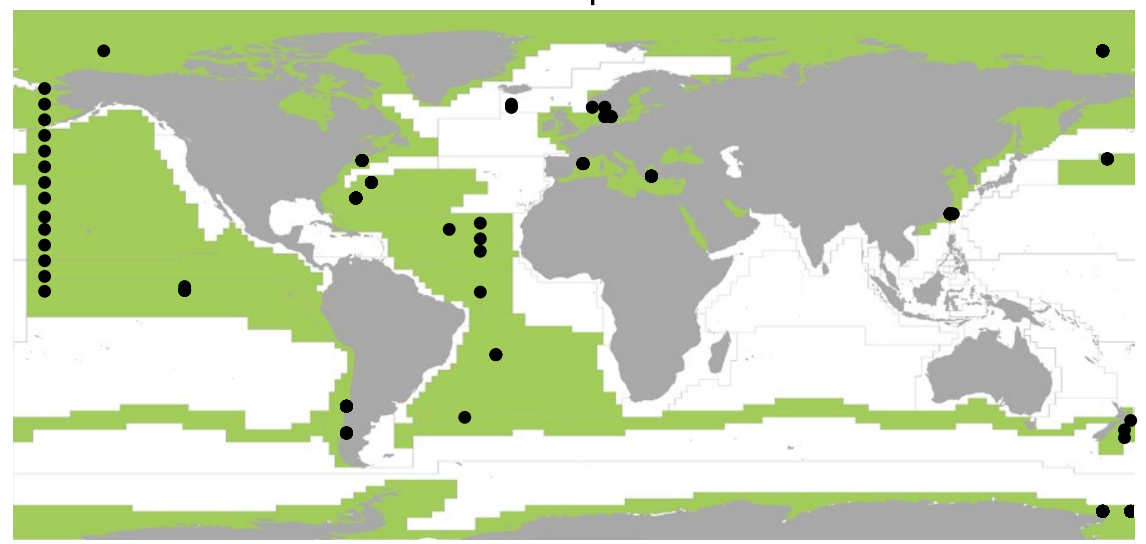

FIGURE 4 Global distribution of constitutive mixotrophs (CMs) with maximum cell dimension $<20 \mu \mathrm{m}$. (a) Records obtained from OBIS (Supporting Information Appendix S2, Table S2.1). (b) Records obtained from studies of protist nanoplankton bacterivory (Supporting Information Appendix S2, Table S2.2). Symbols correspond to the exact location where CMs were found. Colour-cast provinces indicate the presence of $\mathrm{CMs}$, whereas white provinces correspond to absence owing to lack of data; the grid indicates Longhurst's biogeographical provinces (Supporting Information Appendix S1, Table S1.2) [Colour figure can be viewed at wileyonlinelibrary.com]
McKie-Krisberg, Fay, Rose, \& Sanders, 2014; Safi \& Hall, 1999; Sato, Shiozaki, \& Hashihama, 2017). Estimates of bacterivory rates are also problematic because they are based on the assumptions that bacterivory remains constant over the short time scales of incubation studies and that community ingestion rates can be approximated to the average ingestion rate of all feeding individuals (Anderson et al., 2017). In reality, feeding varies over the diel cycle (Tsai, Chin, \& Chiang, 2009), and only a small proportion of the total mixotroph assemblage is actively feeding at any time during an experiment (Anderson et al., 2017; Christaki, Wambeke, \& Dolan, 1999).

The CM species database is biased towards certain species and/ or groups that have been extensively investigated owing to their perceived environmental importance. For example, studies in the coastal regions covering low-salinity, estuarine and marine waters have focused on harmful algal bloom (HAB) or toxic species within the dinophyte taxa (Shumway et al., 2018). Some, if not most, of these HAB species are known mixotrophs (Shumway et al., 2018). Some co-occurring protist species (including competitors, prey and predators) are also known mixotrophs, although many are not often recorded because they are not themselves HAB species. Indeed, of the $80 \mathrm{CM}$ species included within our analysis, 51 species were dinophytes, despite the importance of mixotrophy having been well recognized in other taxonomic groups (Gast et al., 2014; Stoecker \& Lavrentyev, 2018; Unrein et al., 2014).
Biases among records of CMs may also be particularly high owing to differential efforts at sampling CMs of different sizes. It is not common practice to identify to species level in plankton surveys, especially among the smaller flagellate cells that are coincidentally mixotrophic (Sanders \& Gast, 2012; Stoecker \& Lavrentyev, 2018). Incubation experiments have demonstrated ingestion of prey by these small CMs $(<20 \mu \mathrm{m})$, whereas taxonomic identification using traditional diagnostic approaches has been difficult owing to few distinctive features for these species. The available evidence indicates that field studies typically neglect most CMs $<20 \mu \mathrm{m}$. However, mixotrophic pico- and nanoflagellates, for example, have been shown to be abundant and to play a major role as bacterivores and primary producers in oligotrophic oceans (Hartmann, Zubkov, Scanlan, \& Lepère, 2013; Mitra et al., 2014; Zubkov \& Tarran, 2008). Nevertheless, global plankton databases have failed to indicate the ubiquity of these organisms across the global oceans, particularly in the open oceans (Figure 4). In contrast, although dinophytes appear to be important in oligotrophic oceans according to survey data (Figure 1), in fact they are relatively minor contributors to the total abundance and activity of mixotrophic flagellates within these areas (Unrein et al., 2014).

The strong bias towards larger cells and dinophytes is in part also attributed to traditional sampling and preservation methods that are known to underestimate the abundance of more fragile groups or 
smaller size fractions within the plankton (Edwards, Johns, Leterme, Svendsen, \& Richardson, 2006; Gifford \& Caron, 2000). The resultant distorted picture of plankton composition across the oceans (Biard et al., 2016) is typified by, for example, survey data from the historic Continuous Plankton Recorder (CPR), a device best suited (designed) for sampling mesozooplankton and larger (> $250 \mu \mathrm{m}$ in size) robust phytoplankton (Richardson et al., 2006). The CPR cannot capture data for the majority of the non-diatom protist species, an exception being very large dinoflagellates, such as $\mathrm{CMs}$ within the genus Tripos (formally Ceratium). Given the changes in our understanding of marine ecology, with recognition of the increasing importance of the microbial loop and mixotrophic protists, the CPR requires augmentation with a device specifically designed for sampling small protists.

Recent advances in metagenomics and computational analysis allow identification of the taxonomic and genomic content of marine communities, and investigation of their functional potential (Sunagawa et al., 2015). Nevertheless, we could not exploit such datasets in our analysis. Although sequence datasets offer a powerful approach to provide molecular taxonomy in the future, protistologists probably have decades of work ahead of them to match sequence data against morphology/physiology. For the sequence datasets, one of the most problematic issues is converting the data into species information (Bucklin, Lindeque, Rodriguez-Ezpeleta, Albaina, \& Lehtiniemi, 2016; Leray \& Knowlton, 2016). Within the arena of molecular analysis itself, there are different methodologies for obtaining sequence information, so that forming operational taxonomic units (OTUs) from those data is far from standardized (e.g., Callahan, McMurdie, \& Holmes, 2017).

In addition, most mixotrophic protists fall into often closely related groups that are composed of a mixture of species with different nutritional modes (i.e., autotrophic, heterotrophic and mixotrophic). Although metagenomics might offer a means to identify active mixotrophs (Rokitta et al., 2011; Yelton et al., 2016), how to use the potential of metagenomics to differentiate mixotrophs from their autotrophic or heterotrophic counterparts remains to be resolved fully (Santoferrara \& McManus, 2017). Furthermore, OTUs far outnumber the number of morphologically described or nutritionally described species that have been sequenced; at present, there is no way of differentiating the mixotrophs among the many OTUs typically recorded in molecular datasets. Meanwhile, experimental studies continue to provide increasing evidence that more and more species previously thought to be "strictly" photoautotrophic phytoplankton are, in fact, CMs (e.g., Berge et al., 2008; Hoppenrath \& Leander, 2007; Jang et al., 2017; Kamennaya, Kennaway, Fuchs, \& Zubkov, 2018; Kang et al., 2011; Lim et al., 2015; Nézan \& Chomérat, 2009; Ok et al., 2017; Yoo et al., 2010).

In conclusion, our analyses show clearly that CMs of different taxonomic groups and size ranges are present and active throughout the oceans. The oceanic plankton community contributes an estimated $50 \%$ of total planetary primary production. The $\mathrm{CMs}$ are a major contributing component of this community. Therefore, it is important that we are aware of the biogeography of these organisms with reference to their physiology, ecology and seasonality.
Our findings are highly relevant to plankton biogeography, with implications scaling up to the functioning of food webs and biogeochemical cycles in the global oceans. The challenge now facing marine scientists is to develop widely accepted routine protocols for determining mixotrophic potential and improved survey methods for sampling and identifying the smaller plankton members. It is important that developments in plankton protist ecophysiology, traditional and molecular taxonomy, field experimentation and sampling all remain well aligned during the coming decade to ensure that we resolve the global importance of oceanic mixotrophy adequately and speedily. Without this alignment, our abilities to develop and deploy models to explore the consequences of climate change for oceanic (hence planetary) processes will be impaired.

\section{ACKNOWLEDGEMENTS}

This work was part funded through a Leverhulme International Networking Grant (F00391V). S.G.L. is funded by the Brazilian government programme Science Without Borders through CNPq (Conselho Nacional de Desenvolvimento Científico e Tecnológico - Brasil). The University of Dundee is a registered Scottish charity, no. 015096.

\section{DATA ACCESSIBILITY}

Constitutive mixotroph species and the geographical coordinates of studies that specifically targeted CMs are collated within the Supplementary Information (Appendix S1, Table S1.1 and Appendix S2, Table S2.2, respectively). Records for different CM species are available as open access within the OBIS database (http://www. iobis.org/); we also provide this information in the Supporting Information (Appendix S2, Table S2.1). Grids of Longhurst's biogeographical provinces (Supporting Information Appendix S1, Table S1.2) can be downloaded from http://www.marineregions.org/.

\section{ORCID}

Suzana Gonçalves Leles (iD https://orcid.org/0000-0002-7819-5851

Aditee Mitra iD https://orcid.org/0000-0001-5572-9331

Kevin John Flynn (iD http://orcid.org/0000-0001-6913-5884

Patricia M. Glibert (iD https://orcid.org/0000-0001-5690-1674

Gustaaf Hallegraeff iD http://orcid.org/0000-0001-8464-7343

\section{REFERENCES}

Anderson, R., Jürgens, K., \& Hansen, P. J. (2017). Mixotrophic phytoflagellate bacterivory field measurements strongly biased by standard approaches: A case study. Frontiers in Microbiology, 8, 1-12. https:// doi.org/10.3389/fmicb.2017.01398

Berge, T., Hansen, P. J., \& Moestrup, Ø. (2008). Prey size spectrum and bioenergetics of the mixotrophic dinoflagellate Karlodinium armiger. Aquatic Microbial Ecology, 50, 289-299. https://doi.org/10.3354/ ame01166

Biard, T., Stemmann, L., Picheral, M., Mayot, N., Vandromme, P., Hauss, H., ... Not, F. (2016). In situ imaging reveals the biomass of giant protists in the global ocean. Nature, 532, 504-507. https://doi. org/10.1038/nature17652 
Bucklin, A., Lindeque, P. K., Rodriguez-Ezpeleta, N., Albaina, A., \& Lehtiniemi, M. (2016). Metabarcoding of marine zooplankton: Prospects, progress and pitfalls. Journal of Plankton Research, 38, 393-400. https://doi.org/10.1093/plankt/fbw023

Burkholder, J. M., Glibert, P. M., \& Skelton, H. M. (2008). Mixotrophy, a major mode of nutrition for harmful algal species in eutrophic waters. Harmful Algae, 8, 77-93. https://doi.org/10.1016/j.hal.2008.08.010

Callahan, B. J., McMurdie, P. J., \& Holmes, S. P. (2017). Exact sequence variants should replace operational taxonomic units in marker-gene data analysis. ISME Journal, 11, 2639-2643. https://doi.org/10.1038/ ismej.2017.119

Cermeño, P., de Vargas, C., Abrantes, F., \& Falkowski, P. G. (2010). Phytoplankton biogeography and community stability in the ocean. PLoS ONE, 5, https://doi.org/10.1371/journal.pone.0010037

Cermeño, P., \& Falkowski, P. (2009). Controls on diatom biogeography in the ocean. Science, 325, 1539-1542. https://doi.org/10.1126/ science.1174159

Christaki, U., Van Wambeke, F., \& Dolan, J. R. (1999). Nanoflagellates (mixotrophs, heterotrophs and autotrophs) in the oligotrophic eastern Mediterranean: Standing stocks, bacterivory and relationships with bacterial production. Marine Ecology Progress Series, 181, $297-$ 307. https://doi.org/10.3354/meps181297

de Vargas, C., Audic, S., Henry, N., Decelle, J., Mahé, F., Logares, R., ... Karsenti, E. (2015). Eukaryotic plankton diversity in the sunlit ocean. Science, 348, 1261605. https://doi.org/10.1126/science.1261605

Dolan, J. R. (2005). An introduction to the biogeography of aquatic microbes. Aquatic Microbial Ecology, 41, 39-48. https://doi.org/10.3354/ ame041039

Dolan, J. R. (2006). Microbial biogeography? Journal of Biogeography, 33, 199-200. https://doi.org/10.1111/j.1365-2699.2005.01406.x

Ebach, M. C. (2015). Origins of biogeography. New York, NY: Springer.

Edwards, M., Johns, D., Leterme, S. C., Svendsen, E., \& Richardson, A J. (2006). Regional climate change and harmful algal blooms in the northeast Atlantic. Limnology and Oceanography, 51, 820-829. https://doi.org/10.4319/lo.2006.51.2.0820

Flynn, K. J., Stoecker, D. K., Mitra, A., Raven, J. A., Glibert, P. M., Hansen, P. J., ... Burkholder, J. M. (2013). Misuse of the phytoplankton-zooplankton dichotomy: The need to assign organisms as mixotrophs within plankton functional types. Journal of Plankton Research, 35, 3-11. https://doi.org/10.1093/plankt/fbs062

Fuhrman, J. A., Steele, J. A., Hewson, I., Schwalbach, M. S., Brown, M. V., Green, J. L., \& Brown, J. H. (2008). A latitudinal diversity gradient in planktonic marine bacteria. Proceedings of the National Academy of Sciences of the USA, 105, 7774-7778. https://doi.org/10.1073/ pnas.0803070105

Gast, R. J., McKie-Krisberg, Z. M., Fay, S. A., Rose, J. M., \& Sanders, R. W. (2014). Antarctic mixotrophic protist abundances by microscopy and molecular methods. FEMS Microbiology Ecology, 89, 388-401. https:// doi.org/10.1111/1574-6941.12334

Gifford, D. J., \& Caron, D. A. (2000). Sampling, preservation, enumeration and biomass of marine protozooplankton. In R. Harris, P. Wiebe, J. Lenz, H. R. Skjoldal, \& M. Huntley (Eds.), ICES zooplankton methodology manual (pp. 193-221). London, UK: Academic Press.

Glibert, P. M., \& Legrand, C. (2006). The diverse nutritional strategies of harmful algae: Focus on osmotrophy. In E. Granéli \& J. Turner (Eds.), The ecology of harmful algae (pp. 163-175). Berlin: Springer-Verlag.

Hartmann, M., Zubkov, M. V., Scanlan, D. J., \& Lepère, C. (2013). In situ interactions between photosynthetic picoeukaryotes and bacterioplankton in the Atlantic Ocean: Evidence for mixotrophy. Environmental Microbiology Reports, 5, 835-840. https://doi. org/10.1111/1758-2229.12084

Hoppenrath, M., \& Leander, B. S. (2007). Character evolution in polykrikoid dinoflagellates. Journal of Phycology, 43, 366-377. https://doi.org/10.1111/j.1529-8817.2007.00319.x

Jang, S. H., Jeong, H. J., Kwon, J. E., \& Lee, K. H. (2017). Mixotrophy in the newly described dinoflagellate Yihiella yeosuensis: A small, fast dinoflagellate predator that grows mixotrophically, but not autotrophically. Harmful Algae, 62, 94-103. https://doi.org/10.1016/j. hal.2016.12.007

Kamennaya, N. A., Kennaway, G., Fuchs, B. M., \& Zubkov, M. V. (2018) "Pomacytosis"-Semi-extracellular phagocytosis of cyanobacteria by the smallest marine algae. PLoS Biology, 16, e2003502. https://doi. org/10.1371/journal.pbio.2003502

Kang, N. S., Jeong, H. J., Yoo, Y. D., Yoon, E. Y., Lee, K. H., Lee, K., \& Kim, G. (2011). Mixotrophy in the newly described phototrophic dinoflagellate Woloszynskia cincta from western Korean waters: Feeding mechanism, prey species and effect of prey concentration. Journal of Eukaryotic Microbiology, 58, 152-170. https://doi. org/10.1111/j.1550-7408.2011.00531.x

Legendre, P., \& Legendre, L. (1998). Numerical ecology (2nd ed.). Amsterdam: Elsevier.

Leles, S. G., Mitra, A., Flynn, K. J., Stoecker, D. K., Hansen, P. J., Calbet, A., ... Våge, S. (2017). Oceanic protists with different forms of acquired phototrophy display contrasting biogeographies and abundance. Proceedings of the Royal Society B: Biological Sciences, 284, 20170664. https://doi.org/10.1098/rspb.2017.0664

Leray, M., \& Knowlton, N. (2016). Censusing marine eukaryotic diversity in the twenty-first century. Philosophical Transactions of the Royal Society B: Biological Sciences, 371, 20150331. https://doi. org/10.1098/rstb.2015.0331

Lim, A. S., Jeong, H. J., Kim, J. H., Jang, S. H., Lee, M. J., \& Lee, K. (2015). Mixotrophy in the newly described dinoflagellate Alexandrium pohangense: A specialist for feeding on the fast-swimming ichthyotoxic dinoflagellate Cochlodinium polykrikoides. Harmful Algae, 49, 10-18. https://doi.org/10.1016/j.hal.2015.07.010

Lin, S., Zhang, H., Hou, Y., Miranda, L., \& Bhattacharya, D. (2006). Development of a dinoflagellate-oriented PCR primer set leads to detection of picoplanktonic dinoflagellates from Long Island Sound. Applied and Environmental Microbiology, 72, 5626-5630. https://doi. org/10.1128/AEM.00586-06

Longhurst, A. (2007). Ecological geography of the sea (2nd ed.). Burlington, MA: Academic Press.

Malviya, S., Scalco, E., Audic, S., Vincent, F., Veluchamy, A., Poulain, J., ... Bowler, C. (2016). Insights into global diatom distribution and diversity in the world's ocean. Proceedings of the National Academy of Sciences of the USA, 113, E1516-E1525. https://doi.org/10.1073/ pnas.1509523113

Mitra, A., \& Flynn, K. J. (2010). Modelling mixotrophy in harmful algal blooms: More or less the sum of the parts? Journal of Marine Systems, 83, 158-169. https://doi.org/10.1016/j.jmarsys.2010.04. 006

Mitra, A., Flynn, K. J., Burkholder, J. M., Berge, T., Calbet, A., Raven, J. A., ... Zubkov, M. V. (2014). The role of mixotrophic protists in the biological carbon pump. Biogeosciences, 11, 995-1005. https://doi. org/10.5194/bg-11-995-2014

Mitra, A., Flynn, K. J., Tillmann, U., Raven, J. A., Caron, D., Stoecker, D. K., ... Lundgren, V. (2016). Defining planktonic protist functional groups on mechanisms for energy and nutrient acquisition: Incorporation of diverse mixotrophic strategies. Protist, 167, 106-120. https://doi. org/10.1016/j.protis.2016.01.003

Moon-Van Der Staay, S. Y., De Wachter, R., \& Vaulot, D. (2001). Oceanic 18S rDNA sequences from picoplankton reveal unsuspected eukaryotic diversity. Nature, 409, 607-610. https://doi. org/10.1038/35054541

Nézan, E., \& Chomérat, N. (2009). Fragilidium duplocampanaeforme sp. nov. (Dinophyceae): A new phagotrophic dinoflagellate from the French Atlantic coast. European Journal of Protistology, 45, 2-12. https://doi.org/10.1016/j.ejop.2008.04.002

Ok, J. H., Jeong, H. J., Lim, A. S., \& Lee, K. H. (2017). Interactions between the mixotrophic dinoflagellate Takayama helix and common heterotrophic protists. Harmful Algae, 68, 178-191. https://doi. org/10.1016/j.hal.2017.08.006 
Pierce, R. W., \& Turner, J. T. (1993). Global biogeography of marine tintinnids. Marine Ecology Progress Series, 94, 11-26. https://doi. org/10.3354/meps094011

R Core Team. (2017). R: A language and environment for statistical computing. Vienna, Austria: R Foundation for Statistical Computing.

Richardson, A. J., Walne, A. W., John, A. W. G., Jonas, T. D., Lindley, J. A., Sims, D. W., ... Witt, M. (2006). Using continuous plankton recorder data. Progress in Oceanography, 68, 27-74. https://doi.org/10.1016/j. pocean.2005.09.011

Rokitta, S. D., de Nooijer, L. J., Trimborn, S., de Vargas, C., Rost, B., \& John, U. (2011). Transcriptome analyses reveal differential gene expression patterns between the life-cycle stages of Emiliania huxleyi (haptophyta) and reflect specialization to different ecological niches. Journal of Phycology, 47, 829-838. https://doi. org/10.1111/j.1529-8817.2011.01014.x

Safi, K. A., \& Hall, J. A. (1999). Mixotrophic and heterotrophic nanoflagellate grazing in the convergence zone east of New Zealand. Aquatic Microbial Ecology, 20, 83-93. https://doi.org/10.3354/ame020083

Sanders, R. W., \& Gast, R. J. (2012). Bacterivory by phototrophic picoplankton and nanoplankton in Arctic waters. FEMS Microbiology Ecology, 82, 242-253. https://doi.org/10.1111/j.1574-6941.2011.01253.x

Santoferrara, L. F., \& McManus, G. B. (2017). Integrating dimensions of biodiversity in choreotrichs and oligotrichs of marine plankton. European Journal of Protistology, 61, 323-330. https://doi. org/10.1016/j.ejop.2017.04.004

Sato, M., Shiozaki, T., \& Hashihama, F. (2017). Distribution of mixotrophic nanoflagellates along the latitudinal transect of the central North Pacific. Journal of Oceanography, 73, 159-168. https://doi. org/10.1007/s10872-016-0393-x

Shumway, S. E., Burkholder, J. A. M., \& Morton, S. L. (2018). Harmful algal blooms: A compendium desk reference. Hoboken, NJ: John Wiley \& Sons.

Smayda, T. J. (1958). Biogeographical studies of marine phytoplankton. Oikos, 9, 158-191. https://doi.org/10.2307/3564763

Stoecker, D. K., Hansen, P. J., Caron, D. A., \& Mitra, A. (2017). Mixotrophy in the marine plankton. Annual Review of Marine Science, 9, 311-335. https://doi.org/10.1146/annurev-marine-010816-060617

Stoecker, D. K., \& Lavrentyev, P. J. (2018). Mixotrophic plankton in the polar seas: A pan-arctic review. Frontiers in Marine Science, 5, https:// doi.org/10.3389/fmars.2018.00292.

Sunagawa, S., Coelho, L. P., Chaffron, S., Kultima, J. R., Labadie, K., Salazar, G., ... Bork, P. (2015). Ocean plankton. Structure and function of the global ocean microbiome. Science, 348, 12612359. https://doi. org/10.1126/science.1261359

Tomas, C. R. (1997). Identifying marine phytoplankton. San Diego, CA: Academic Press.

Tsai, A.-Y., Chin, W.-M., \& Chiang, K.-P. (2009). Diel patterns of grazing by pigmented nanoflagellates on Synechococcus spp. in the coastal ecosystem of subtropical western Pacific. Hydrobiologia, 636, 249-256. https://doi.org/10.1007/s10750-009-9954-y

Unrein, F., Gasol, J. M., Not, F., Forn, I., \& Massana, R. (2014). Mixotrophic haptophytes are key bacterial grazers in oligotrophic coastal waters. The ISME Journal, 8, 164-176. https://doi.org/10.1038/ ismej.2013.132

Wilken, S., Huisman, J., Naus-Wiezer, S., \& Van Donk, E. (2013). Mixotrophic organisms become more heterotrophic with rising temperature. Ecology Letters, 16, 225-233. https://doi.org/10.1111/ ele.12033

Yelton, A. P., Acinas, S. G., Sunagawa, S., Bork, P., Pedrós-Alió, C., \& Chisholm, S. W. (2016). Global genetic capacity for mixotrophy in marine picocyanobacteria. ISME Journal, 10, 2946-2957. https://doi. org/10.1038/ismej.2016.64

Yoo, Y. D., Jeong, H. J., Kang, N. S., Kim, J. S., Kim, T. H., \& Yoon, E. Y. (2010). Ecology of Gymnodinium aureolum. II. Predation by common heterotrophic dinoflagellates and a ciliate. Aquatic Microbial Ecology, 59, 257-272. https://doi.org/10.3354/ame01401
Zubkov, M. V., \& Tarran, G. A. (2008). High bacterivory by the smallest phytoplankton in the North Atlantic Ocean. Nature, 455, 224-226. https://doi.org/10.1038/nature07236

\section{BIOSKETCH}

The research team comprises an international group of experts in field, laboratory and modelling aspects of mixotrophic plankton. This team, with others, has been at the forefront of the recent establishment of a revised paradigm in marine ecology that recognizes that the majority of eukaryote organisms traditionally considered as pure phototrophic "phytoplankton" or pure heterotrophic "microzooplankton", are in fact mixotrophic, combining photo- and phagotrophy. The concept of mapping different mixotroph functional groups originated and was then developed through successive meetings funded by a Leverhulme International Networking Grant (F00391V) "Placing Marine Mixotrophs in Context". The first author is a PhD student of A.M. and K.J.F., who led that Leverhulme project.

\section{SUPPORTING INFORMATION}

Additional supporting information may be found online in the Supporting Information section at the end of the article.

How to cite this article: Leles SG, Mitra A, Flynn KJ, et al. Sampling bias misrepresents the biogeographical significance of constitutive mixotrophs across global oceans. Global Ecol Biogeogr. 2019;28:418-428. https://doi.org/10.1111/ geb.12853

\section{APPENDIX 1}

Reference list of studies that specifically targeted CMs but are not cited within the main text (see also Supporting Information Appendix S2, Table S2.2)

Arenovski, A. L., Lim, E. L., \& Caron, D. A. (1995). Mixotrophic nanoplankton in oligotrophic surface waters of the Sargasso Sea may employ phagotrophy to obtain major nutrients. Journal of Plankton Research, 17, 801-820.

Czypionka, T., Vargas, C. A., Silva, N., Daneri, G., González, H. E., \& Iriarte, J. L. (2011). Importance of mixotrophic nanoplankton in Aysén Fjord (Southern Chile) during austral winter. Continental Shelf Research, 31, 216-224.

Hall, J. A., Barrett, D. P., \& James, M. R. (1993). The importance of phytoflagellate, heterotrophic flagellate and ciliate grazing on bacteria and picophytoplankton sized prey in a coastal marine environment. Journal of Plankton Research, 15, 1075-1086.

Hartmann, M., Grob, C., Tarran, G. Martin, A. P., Burkill, P. H., Scanlan, D. J. \& Zubkov, M. A. (2012). Mixotrophic basis of Atlantic oligotrophic ecosystems. Proceedings of the National Academy of Sciences of the USA, 109, 5756-5760.

Havskum, H., \& Hansen, A. S. (1997). Importance of pigmented and colourless nano-sized protists as grazers on nanoplankton in a phosphate-depleted Norwegian fjord and in enclosures. Aquatic Microbial Ecology, 12, 139-151. 
Havskum, H., \& Riemann, B. (1996). Ecological importance of bacterivorous, pigmented flagellates (mixotrophs) in the Bay of Aarhus, Denmark. Marine Ecology Progress Series, 137, 251-263.

Moorthi, S., Caron, D. A., Gast, R. J., \& Sanders, R. W. (2009). Mixotrophy: A widespread and important ecological strategy for planktonic and sea-ice nanoflagellates in the Ross Sea, Antarctica. Aquatic Microbial Ecology, 54, 269-277.

Nygaard, K., \& Tobiesen, A. (1993). Bacterivory in algae: A survival strategy during nutrient limitation. Limnology and Oceanography, 38, 273-279.

Sanders, R. W., Berninger, U. G., Lim, E. L., Kemp, P. F., \& Caron, D. A. (2000). Heterotrophic and mixotrophic nanoplankton predation on picoplankton in the Sargasso Sea and on Georges Bank. Marine Ecology Progress Series, 192, 103-118.

Sanders, R. W., \& Gast, R. J. (2012). Bacterivory by phototrophic picoplankton and nanoplankton in Arctic waters. FEMS Microbiology Ecology, 82, 242-253.
Stukel, M. R., Landry, M. R., \& Selph, K. E. (2011). Nanoplankton mixotrophy in the eastern equatorial Pacific. Deep-Sea Research Part II: Topical Studies in Oceanography, 58, 378-386.

Tsai, A. Y., Gong, G. C., Sanders, R. W., Chen, W. H., Chao, C. F., \& Chiang, K. P. (2011). Importance of bacterivory by pigmented and heterotrophic nanoflagellates during the warm season in a subtropical western Pacific coastal ecosystem. Aquatic Microbial Ecology, 63, 9-18.

Unrein, F., Massana, R., Alonso-Sáez, L., \& Gasol, J. M. (2007). Significant yearround effect of small mixotrophic flagellates on bacterioplankton in an oligotrophic coastal system. Limnology and Oceanography, 52, 456-469.

Vargas, C., Contreras, P., \& Iriarte, J. (2012). Relative importance of phototrophic, heterotrophic, and mixotrophic nanoflagellates in the microbial food web of a river-influenced coastal upwelling area. Aquatic Microbial Ecology, 65, 233-248. 